\title{
Influence of respiratory viruses on the evaluation of the 13-valent pneumococcal conjugate vaccine effectiveness in children under 5 years old: A time-series study for the 2001-2013 period
}

\author{
Angela Gentile, M.D. ${ }^{a}$, María del Valle Juárez, M.D. ${ }^{a}$, María Florencia Lución, M.D. ${ }^{a}$, \\ Viviana Sandra Romanin, M.D. ${ }^{a}$, Norberto Giglio, M.D. ${ }^{a}$, and Julia Bakir, M.D. ${ }^{a}$
}

\begin{abstract}
Introduction. Streptococcus pneumoniae is the main agent in bacterial consolidated pneumonias. In 2012, the 13-valent pneumococcal conjugate vaccine was introduced in the Argentinenational immunization schedule for immunocompetent children as of two months old with a two-dose schedule plus a booster.

Objective.To analyze the influence of respiratory viruses on the evaluation of the 13-valent pneumococcal conjugate vaccine effectiveness in relation to the number of hospitalizations for radiologically-confirmed consolidated pneumonias (RCCP).

Methods. Observational, analytical, timeseries study. All children hospitalized with a diagnosis of RCCP as per the World Health Organization's criteria between March and November throughout the 2001-2013 period were included. Viral diagnosis (respiratory syncytial virus, adenovirus, influenza and parainfluenza) was performed by indirect immunofluorescence using nasopharyngeal aspirates or by reverse transcription polymerase chain reaction. Time-series were developed to compare preimmunization 2001-2011 and post-immunization 2012-2013 periods.
\end{abstract}

Results. Out of a total of 11,306 children under 5 years old with acute lower respiratory tract infections, 4974 with RCCP were included. Annual average number of hospitalizations for RCCP: 394.8 pre-immunization, 315.5 post-immunization (reduction of $20.1 \%$, 95\% confidence interval [CI]: 13.13-26.49\%, $p<0.001$ ). Annual average number of hospitalizations for non-viral RCCP: 255.5 pre-immunization, 183 post-immunization (reduction of $28.4 \%, 95 \%$ CI: $20.5-35.78 \%, p<0.001)$. Annual average number of hospitalizations for viral RCCP: 139.2 pre-immunization, 132 post-immunization (reduction of $4.8 \%, 95 \%$ CI: $8.38-16.49 \%$, $p=0.4758$ ). The proportion of RCCP with positive viral diagnosis was $35.3 \%$ pre-immunization and $42 \%$ post-immunization $(p=0.001)$.

Conclusions. An overall significant reduction in the number of hospitalizations for RCCP was observed following the introduction of the 13-valent pneumococcal conjugate vaccine, especially in the case of non-viral pneumonias. It is critical to continue with the epidemiological surveillance to evaluate the impact of this intervention and viral behavior in relation to RCCP.
Key words: pneumonia, Streptococcus pneumoniae, pneumococcal vaccines, time-series studies, effectiveness.

http:/ /dx.doi.org/10.5546/aap.2015.eng.310

\section{INTRODUCTION}

Pneumococcal infections are a major cause of morbidity, hospitalization and mortality around the world, with two age groups affected by the greatest incidence and severity: children younger than 2 years old and adults older than 65 years old. ${ }^{1}$

The World Health Organization (WHO) estimated in 2000 that $20 \%$ of deaths in children under 5 years old were related to acute respiratory infections; $90 \%$ of these corresponded to community-acquired acute pneumonias, and $50 \%$ of these were caused by Streptococcus pneumoniae., ${ }^{2,3}$ In Argentina, respiratory diseases are the third cause of death among children under 5 years old, with a hospitalization rate of approximately $65 \%$ and a fatality rate of $1.1 \% .^{4-6}$

In 2012, Argentina introduced the 13-valent pneumococcal conjugate vaccine (PCV13) in the national immunization schedule with the purpose of managing invasive pneumococcal disease (IPD) and reducing mortality from pneumonia, and their respective sequelae.

Immunization coverage data as per the WHO were, for 2012, a $69 \%$ coverage with the first dose and a $22 \%$ with the third dose, and for 2013, a $96 \%$ coverage with the first dose and an $81 \%$ with the booster dose. ${ }^{7}$

In terms of serotypes circulating in 
Argentina, the PCV13 has a coverage of $85 \%$ for all pneumococcal diseases, $88.4 \%$ for pneumoniaassociated serotypes, and $83.3 \%$ for meningitis, according to the data provided by the Surveillance System for the Bacterial Agents Responsible for Pneumonia and Meningitis (SIREVA II) for 2011. ${ }^{8}$

As in different countries worldwide, ${ }^{9-11}$ once the PCV13 was introduced in the national immunization schedule, guidelines were implemented to assess its effectiveness in the "real world."12,13

Given the difficulty to confirm the bacterial diagnosis of the disease caused by Streptococcus pneumoniae, clinical and radiological patterns have provided adequate information to perform different studies on effectiveness. ${ }^{3}$

In relation to the measurement of the pneumococcal vaccine efficacy and effectiveness in terms of reduction of radiologically-confirmed consolidated pneumonia (RCCP), there is a controversy about what the positive predictive value is to infer a bacterial infection considering viruses' capability to produce radiological images of consolidation similar to those caused by bacterial agents.

Based on the above mentioned, we consider that it is interesting for effectiveness studies to evaluate the influence of viruses on RCCPs.

The objective of this study is to analyze the influence of respiratory viruses on the evaluation of the 13-valent pneumococcal conjugate vaccine effectiveness in relation to the number of hospitalizations for RCCP.

\section{MATERIAL AND METHODS}

Observational, analytical, time-series study. Children under 5 years old hospitalized between March and November throughout the 2001-2013 period with a diagnosis of RCCP for all causes as per the WHO's definitions for 2000 were included. ${ }^{3}$

All records of RCCP were obtained from the Active Epidemiological Surveillance Program of Hospital de Niños Ricardo Gutiérrez.

This program has been in place at the hospital since 2000 and consists of an active and prospective epidemiological surveillance of acute lower respiratory tract infections (ALRTIs) in children hospitalized for this cause. At the time of hospital admission, a chest $\mathrm{x}$-ray and viral tests are performed.

Inclusion criterion: patients under 5 years old hospitalized at our institution with a diagnosis of RCCP upon admission.
Exclusion criterion: patients hospitalized for a different cause who developed RCCP after 48 hours of admission.

RCCP: dense opacity, usually homogenous or cotton wool-like, involving a section of or an entire lung lobe, generally with an air bronchogram and sometimes in association with pleural effusion.

RCCP with viral detection: radiologicallyconfirmed consolidated pneumonia, subjected to a lab test (indirect immunofluorescence) in the first 48 hours of hospital admission with a positive result.

The viral diagnosis -respiratory syncytial virus (RSV), adenovirus, influenza and parainfluenzawas performed by indirect immunofluorescence (IIF) or by reverse transcription polymerase chain reaction (RT-PCR) for influenza (as of 2009) using nasopharyngeal aspirates in the first 48 hours of hospitalization.

In this study, the 2001-2011 period was defined as the pre-immunization period, and 2012-2013 was established as the post-immunization period.

First of all, a descriptive analysis was done estimating the median and interquartile range for continuous variables, and proportions and corresponding $95 \%$ confidence intervals (CI) for categorical data. A time-series methodology was used, and rolling means were estimated to compare pre- and post-immunization periods, and viral detection was used as point of comparison.

In addition, a stratified analysis was performed for the time-series proposed in terms of children under 1 year old and of RCCP with positive viral diagnosis detected by indirect immunofluorescence.

Weather data: Monthly temperature and relative humidity mean values of the Central Observatory of Buenos Aires for the 2001-2013 period were provided by the National Weather Department, Ministry of Defense. Temperature was expressed in degrees Celsius $\left({ }^{\circ} \mathrm{C}\right)$ and relative humidity in percentage.

This study was approved by the Research Ethics Committee of Hospital de Niños Ricardo Gutiérrez.

\section{RESULTS}

Between 2001 and 2013, a total of 11306 children under 5 years old were hospitalized for ALRTI; of them, 4974 were admitted with a diagnosis of RCCP. The characteristics of patients hospitalized for RCCP in our site described a population 
largely made up of children under 2 years old, with an equal sex distribution, mostly living in Greater Buenos Aires, and with no significant differences between both periods (Table 1).

In the sample of patients with RCCP as per the viral diagnosis, $63.8 \%(n=3177)$ showed negative viral diagnosis, while $36.2 \%(n=1797)$ had a positive viral diagnosis.

The time-series of RCCP and respiratory virus cases evidenced a similar seasonal pattern, with predominance in the winter. The periods of peak viral detection matched, across all years, the periods of higher humidity and lower temperature values. Likewise, the highest viral detection was consistent with peaks in hospitalization of RCCP cases. RCCPs without viral detection were predominant in spring, except in 2013, when such predominance was no longer observed outside the highest detection period (Figure 1).

The annual average number of hospitalizations for RCCP in the pre-immunization period was 394.8 (SD 54.6). The average in the postimmunization period was 315.5 (SD 36.1), which accounted for a $20.1 \%$ reduction $(95 \%$ CI: $13.13-$ $26.49 \% ; p<0.001)$ from the pre-immunization period. When analyzing the population of infants under 1 year old, such reduction was 22\% (95\% CI: $12.4-31.5 \% ; p<0.001$ ).

The annual average number of hospitalizations for non-viral RCCP was 255.5 (SD 31.5) in the preimmunization period and 183 (SD 32.5) in the post-immunization period, which accounted for a $28.4 \%$ reduction (95\% CI: $20.5-35.78 \%$ ), which was statistically significant $(p<0.001)$. The annual average number of hospitalizations for viral RCCP was 139.2 (SD 36.5) in the preimmunization period and 132 (SD 3.5) in the post-immunization period. This showed a $4.8 \%$ reduction, with no statistical significance (Table 2).

The proportion of consolidated pneumonias with viral diagnosis was $35.3 \%(1532 / 4343)$ in the pre-immunization period, and $42 \%(265 / 631)$ in the post-immunization period. Such difference between both proportions was significant $(p=0.0010)$ (Figure 2).

\section{DISCUSSION}

Our results evidence a reduction in the number of cases of RCCP with hospitalization, and also demonstrate that the inclusion of RCCP cases with positive viral diagnosis modifies results of the effectiveness of PCV13 for the 20122013 period in Argentina.

Values of effectiveness are consistent with other studies, such as the one on the efficacy of the 7-valent vaccine conducted by Black, et al., ${ }^{14,15}$ which showed a $25.5 \%$ reduction of RCCP.

In this regard, Grijalva has described a 39\% reduction using interrupted time-series excluding the transition year and using secondary source data. ${ }^{11}$

In relation to the differences observed in terms of effectiveness for RCCP and RCCP with a positive and negative viral diagnosis, Dagan, et al. ${ }^{16}$ demonstrated that the introduction of PCV in their national immunization schedules has caused a significant reduction in the number of RCCP cases, which is even higher when such

TABLE 1. Characteristics of patients hospitalized for radiologically-confirmed consolidated pneumonia. Pre-immunization (2001-2011) and post-immunization (2012-2013) periods. Hospital de Niños R. Gutiérrez

\begin{tabular}{lcc}
\hline Population characteristics $^{1}$ & $\begin{array}{c}\text { Pre-immunization (n= 4343) } \\
\text { \% (n) }\end{array}$ & $\begin{array}{c}\text { Post-immunization (n= 631) } \\
\text { \% (n) }\end{array}$ \\
\hline Age (median age in months) & $12(1-59)$ & $12(1-58)$ \\
Younger than 1 year old & $47.6 \%(2066)$ & $46.3 \%(292)$ \\
Younger than 2 years old & $74.8 \%(3251)$ & $75.2 \%(458)$ \\
Sex (male) & $55.5 \%(2407)$ & $50.4 \%(318)$ \\
Origin (province of Buenos Aires) & $74.4 \%(3220)$ & $76.8 \%(485)$ \\
Prematurity (<37 weeks) & $14.8 \%(642)$ & $15.2 \%(96)$ \\
Perinatal history related & & $13.9 \%(88)$ \\
to respiratory diseases & $13.1 \%(567)$ & $6.2 \%(39)$ \\
Malnutrition (2 $2^{\text {nd }}-3^{\text {rd }}$ degree) & $7.8 \%(340)$ & $3.3 \%(21)$ \\
Immunosupression & $4.6 \%(200)$ & $43.2 \%(271)$ \\
Prior hospitalizations due to respiratory causes & $43.3 \%(1881)$ & \\
\hline
\end{tabular}

${ }^{1}$ No significant differences observed in population characteristics between both periods. 
FIGURE 1. Hospitalizations for radiologically-confirmed consolidated pneumonia and viral detection in relation to seasonal variations in children under 5 years old. Hospital de Niños R. Gutiérrez 2001-2013

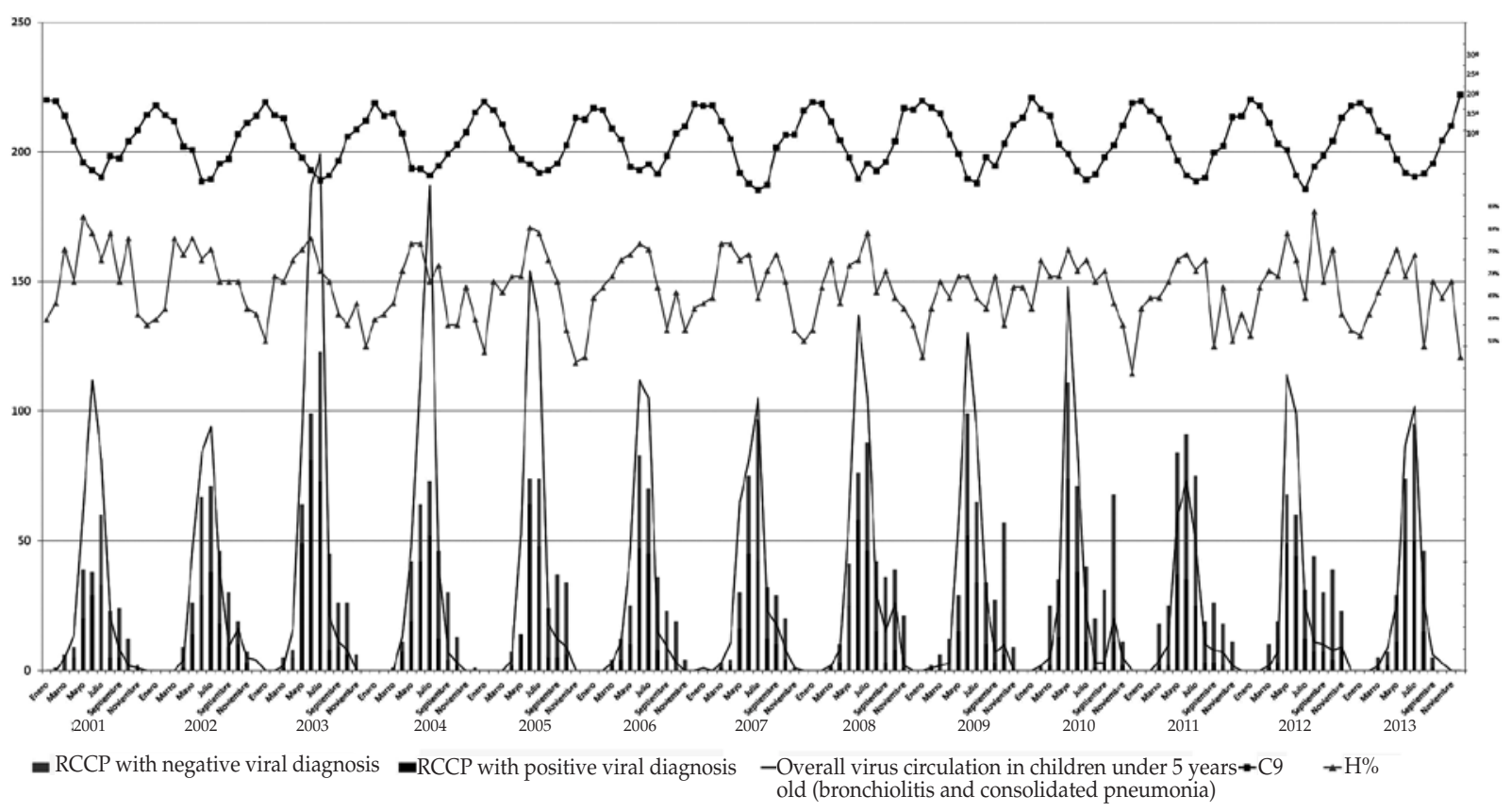

RCCP: radiologically-confirmed consolidated pneumonias.

TABLE 2. Cases and annual average of radiologically-confirmed consolidated pneumonia cases and as per viral rescue in children under 5 years old. Hospital de Niños R. Gutiérrez 2001-2013

\begin{tabular}{|c|c|c|c|c|c|c|c|}
\hline \multicolumn{8}{|c|}{ Younger than 5 years old } \\
\hline \multirow[t]{2}{*}{ Period } & \multicolumn{2}{|c|}{ Pre-PCV13 (2001-2011) } & \multicolumn{2}{|c|}{ Post-PCV13 (2012-2013) } & \multirow{2}{*}{$\begin{array}{c}\text { Reduction } \\
\%\end{array}$} & \multirow[t]{2}{*}{$95 \%$ CI } & \multirow[t]{2}{*}{$\mathbf{p}$} \\
\hline & Cases & Annual average & Cases & $\begin{array}{l}\text { Annual } \\
\text { average }\end{array}$ & & & \\
\hline RCCP & 4343 & 394.8 & 631 & 315.5 & 20.1 & $13.13-26.49$ & 0.0000 \\
\hline $\begin{array}{l}\text { RCCP with negative } \\
\text { viral diagnosis }\end{array}$ & 2811 & 255.5 & 366 & 183.0 & 28.4 & $20.5-35.78$ & 0.0000 \\
\hline $\begin{array}{l}\text { RCCP with positive } \\
\text { viral diagnosis }\end{array}$ & 1532 & 139.2 & 265 & 132.0 & 5.2 & $-8.38-16.49$ & 0.547 \\
\hline \multicolumn{8}{|c|}{ Younger than 1 year old } \\
\hline \multirow[t]{2}{*}{ Period } & \multicolumn{2}{|c|}{ Pre-PCV13 (2001-2011) } & \multicolumn{2}{|c|}{ Post-PCV13 (2012-2013) } & Reduction & $95 \% \mathrm{CI}$ & $\mathrm{p}$ \\
\hline & Cases & Annual average & Cases & $\begin{array}{l}\text { Annual } \\
\text { average }\end{array}$ & $\%$ & & \\
\hline RCCP & 2066 & 187.8 & 291 & 145.5 & 22.6 & $12.4-31.5$ & 0.0000 \\
\hline $\begin{array}{l}\text { RCCP with negative } \\
\text { viral diagnosis }\end{array}$ & 1165 & 105.9 & 151 & 75.5 & 28.7 & $15.5-39.8$ & 0.0000 \\
\hline $\begin{array}{l}\text { RCCP with positive } \\
\text { viral diagnosis }\end{array}$ & 901 & 81.9 & 140 & 70.0 & 14.5 & $-30.5-18$ & 0.0000 \\
\hline
\end{tabular}

PCV13: 13-valent pneumococcal conjugate vaccine; RCCP: radiologically-confirmed consolidated pneumonias. 
result is adjusted by the seasonal variation of the respiratory syncytial virus.

From a unicist perspective, it is plausible to consider that, given the characteristics of pneumococcal conjugate vaccines, they may have no impact on viral pneumonias. Due to this situation, the effect might be underestimated or overestimated when including this clinical condition in effectiveness studies.

Contrary to the preceding information, Klugman, et al., ${ }^{17}$ conducted a randomized controlled study in Soweto and described, in the per protocol analysis, an efficacy of 17\% (95\% CI: 2-30) for lobar pneumonia for any cause, of $14 \%$ (95\% CI: $2-24)$ for pneumonias with no viral identification, and of $31 \%$ (95\% CI: 15-43) for viral pneumonias. The author justifies the efficacy of the PCV9 for radiologically-confirmed pneumonia with positive viral diagnosis based on the hypothesis of viral and bacterial co-infection in this type of respiratory condition.

RCCP with positive viral diagnosis and viral and bacterial co-infection in lower respiratory tract infections have been approached by different authors. ${ }^{18-20}$ A population-based study conducted in Uruguay by Hortal, et al. ${ }^{21}$ before introducing the pneumococcal vaccine demonstrated that
$17.1 \%$ of non-consolidated pneumonias evidenced some viral detection, and that $18 \%$ of the consolidating (or probably bacterial) pneumonias presented a viral diagnosis. It is worth noting that the viral etiology was established at random, not in all the cases.

A study published by Gentile, et al. ${ }^{22}$ in the context of the National Infectious Disease Committee of the Argentine Society of Pediatrics, which describes the experience and actions taken in the pandemic influenza period, observed that $47.6 \%$ of patients hospitalized with the diagnosis of pandemic influenza had consolidated pneumonia.

Studies conducted in indigenous communities of Central Australia have found a 39.8\% rate of viral and bacterial co-infections, and the author has not been able to demonstrate a characteristic pattern of infection based on the nasal detection of respiratory viruses and bacteria among radiologically-confirmed pneumonias and other lower respiratory tract infections..$^{23}$

In this regard, a study conducted in France showed that $28 \%$ of children hospitalized for community-acquired pneumonia had viral and bacterial co-infections. ${ }^{24}$

Similar results have been described by

FIGURE 2. Annual number of consolidated pneumonia cases as per viral diagnosis and proportion of radiologically-confirmed consolidated pneumonias with positive and negative viral diagnoses for the 2001-2013 period

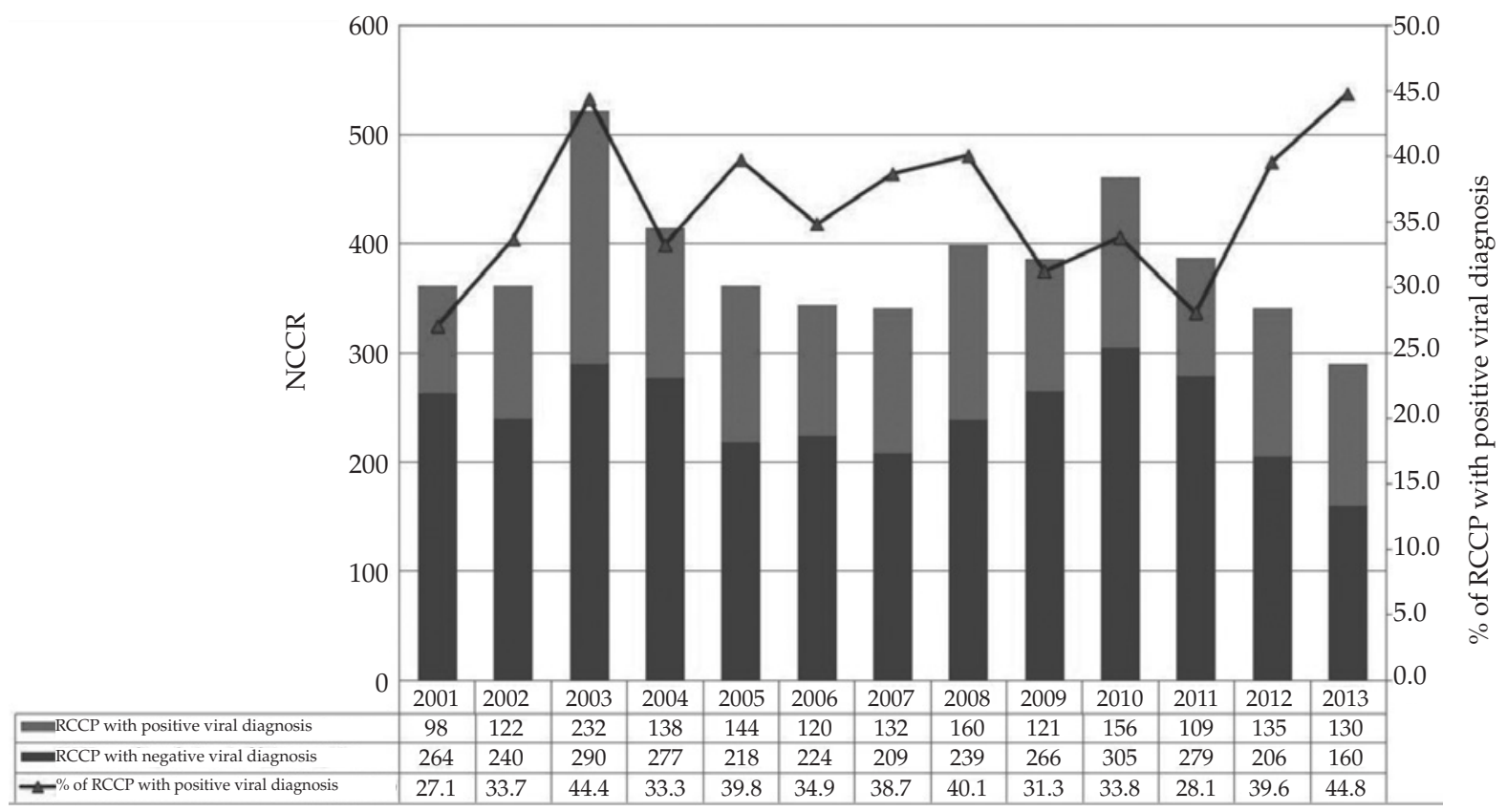

RCCP: radiologically-confirmed consolidated pneumonias. 
Luchsinger, et al. ${ }^{25}$ in a study conducted in an adult population of Chile. In this study, the authors mentioned a co-infection with community-acquired pneumonia caused by Streptococcus pneumoniae and respiratory viruses in 25 cases out of an overall sample of 356 cases.

Finally, our study has certain weaknesses in terms of the evaluated effectiveness. In relation to the pre-introduction period, the year of the pandemic was included, and this may overestimate the diagnosis of consolidated pneumonia. In addition, the period following the introduction of the vaccine is brief; with the inclusion of more years in this period, estimations of effectiveness will certainly be stronger.

Given the characteristics of our work, we have not been able to study co-infections because the detection of bacteria in this clinical condition is low, so it is not possible to rule out co-infections.

Conditions such as the type of study design or the number of viral pneumonia cases assessed may account for the lack of impact on the latter group should the hypothesis of co-infection have no relevance.

This poses a new controversy because, to date, detecting a virus in a lobar pneumonia is not enough to rule out a Streptococcus pneumoniae coinfection in those clinical conditions. ${ }^{26}$

Studies with stronger internal validity are necessary to confirm these hypotheses.

\section{CONCLUSIONS}

A significant reduction in the number of hospitalizations for RCCP was observed following the introduction of the PCV13 in the national immunization schedule, especially in relation to RCCP with negative viral diagnosis; and no significant effectiveness values were observed in association with RCCP with positive viral diagnosis.

\section{REFERENCES}

1. Gorrotxategi Gorrotxategi PJ, Iturrioz Mata A. Vacuna conjugada contra neumococo ¿es una prevención universal adecuada de la enfermedad neumocócica? Rev Pediatr Aten Primaria 2010;12(47):443-55.

2. World Health Organization. Global Health Observatory data. Care seeking for pneumonia. Situation and trends. Geneva, 2015. [Accessed on: March 9, 2015]. Available at: http://www.who.int/gho/child_health/prevention/ pneumonia_text/en/index.html.

3. World Health Organization Pneumonia Vaccine Trial Investigators' Group. Standardization of interpretation of chest radiographs for the diagnosis of pneumonia in children. Geneva, 2001. [Accessed on: March 9, 2015]. Available at: http://apps.who.int/iris / bitstream/10665/66956/1/WHO_V_and_B_01.35.pdf.

4. DireccióndeEstadísticaseInformación deSalud. Estadísticas vitales. Información básica - Año 2012. Buenos Aires: Ministerio de Salud de la Nación Argentina; 2013. Serie 5 Número 56.

5. Gentile A, Ruvinsky R, Bakir J, Gentile F, et al. Probable bacterial pneumonia in children less than five years old in two geographical areas of Argentina: two years of surveillance. En: 44th Interscience Conference on Antimicrobial Agents and Chemotherapy. Washington DC, USA: 2004 Oct 30 - Nov 2.

6. Gaiano A, Biscayart C, VizzottiC. Introducción dela vacuna conjugada antineumocócica en el Calendario Nacional de Vacunación en Argentina. Rev Argent Salud Pública 2012;3(10):41-3.

7. World Health Organization. WHO vaccine-preventable diseases: monitoring system. 2014 global summary. Coverage time series for Argentina. Geneva, 2014. [Accessed on: March 9, 2015]. Available at: http://apps. who.int/immunization_monitoring/globalsummary/ coverages?c=ARG.

8. Organización Panamericana dela Salud. Informe Regional de SIREVA II, 2011: datos por país y por grupos de edad sobre las características de los aislamientos de Streptococcus pneumoniae, Haemophilus influenzae y Neisseria meningitidis, en procesos invasores. Washington DC, 2012.

9. Grijalva CG, Griffin MR. Population-based impact of routine infant immunization with pneumococcal conjugate vaccine in the USA. Expert Rev Vaccines 2008;7(1):83-95.

10. Pirez MC, Algorta G, Cedres A, Sobrero H, et al. Impact of universal pneumococcal vaccination on hospitalizations for pneumonia and meningitis in children in Montevideo, Uruguay. Pediatr Infect Dis J 2011;30(8):669-74.

11. Grijalva CG, Nuorti JP, Arbogast PG, Martin SW, et al. Decline in pneumonia admissions after routine childhood immunisation with pneumococcal conjugate vaccine in the USA: a time-series analysis. Lancet 2007;369(9568):1179-86.

12. Patel MM, Steele D, Gentsch JR, Wecker J, et al. Real-world impact of rotavirus vaccination. Pediatr Infect Dis J 2011;30(1 Suppl):S1-5.

13. Griffin MR, Zhu Y, Moore MR, Whitney CG, et al. U.S. hospitalizations for pneumonia after a decade of pneumococcal vaccination. N Engl J Med 2013;369(2):155-63.

14. Black S, Shinefield H, Fireman B, Lewis E, et al. Efficacy, safety and immunogenicity of heptavalent pneumococcal conjugate vaccine in children. Pediatr Infect Dis J 2000;19(3):187-95.

15. Hansen J,BlackS,Shinefield H,Cherian T, etal. Effectiveness of heptavalent pneumococcal conjugate vaccine in children younger than 5 years of age for prevention of pneumonia: updated analysis using World Health Organization standardized interpretation of chest radiographs. Pediatr Infect Dis J 2006;25(9):779-81.

16. Weinberger DM, Givon-Lavi N, Shemer-Avni Y, Bar-Ziv J, et al. Influence of pneumococcal vaccines and respiratory syncytial virus on alveolar pneumonia, Israel. Emerg Infect Dis 2013;19(7):1084-91.

17. MadhiSA, Klugman KP, Vaccine Trialist Group. A role for Streptococcus pneumoniae in virus-associated pneumonia. Nat Med 2004;10(8):811-3.

18. WolfDG, Greenberg D, Shemer-Avni Y,Givon-LaviN, etal. Association of humanmetapneumoviruswithradiologically diagnosed community-acquired alveolar pneumonia in young children. J Pediatr2010;156(1):115-20.

19. MadhiSA, Ludewick H, Kuwanda L, Van Niekerk N, et al. Pneumococcal coinfection with human metapneumovirus. J Infect Dis 2006;193(9):1236-43.

20. Madhi SA, Kuwanda L, Cutland C, Klugman KP. The impact of a 9-valent pneumococcal conjugate vaccine on the public health burden of pneumonia in HIV infected 
and uninfected children. Clin Infect Dis 2005;40(10):1511-8.

21. Hortal M, Estevan M, Iraola I, De Mucio B. A populationbased assessment of the disease burden of consolidated pneumonia in hospitalized children under five years of age. Int J Infect Dis 2007;11(3):273-7.

22. Gentile A, Bakir J, Russ C, Ruvinsky S, et al. Estudio de las enfermedades respiratorias por virus Influenza A H1N1 (pH1N1) en niños internados durante el año de la pandemia. Experiencia de 34 centros en la Argentina. Arch Argent Pediatr 2011;109(3):198-203.

23. O'Grady K, Torzillo PJ, Valery P, Smith-Vaughan H, et al. Viruses and bacteria associated with hospitalized, radiologically confirmed pneumonia in aboriginal children aged less than five years in Central Australia [abstract].
En: 9th International Symposium on Pneumococci and Pneumococcal Diseases. Hyderabad, India: 2014 March 9-13; p. 46.

24. Cantais A, Mory O, Pillet S, Verhoeven PO, et al. Epidemiology and microbiological investigations of community-acquired pneumonia in children admitted at the emergency department of a university hospital. J Clin Virol 2014;60(4):402-7.

25. Luchsinger V, Ruiz M, Zunino E, Martínez MA, et al. Community-acquired pneumonia in Chile: the clinical relevance in the detection of viruses and atypical bacteria. Thorax 2013;68(11):1000-6.

26. McCullersJA. The co-pathogenesis of influenza viruses with bacteria in the lung. Nat Rev Microbiol 2014;12(4):252-62. 